The Ways of the Word 



\title{
The Ways of The Word
}

\author{
Episodes in Verbal Attention
}

\author{
GarRetT STEWART
}

Cornell University Press

ITHACA AND LONDON 


\section{Copyright @ 2021 by Cornell University}

All rights reserved. Except for brief quotations in a review, this book, or parts thereof, must not be reproduced in any form without permission in writing from the publisher. For information, address Cornell University Press, Sage House, 512 East State Street, Ithaca, New York 14850. Visit our website at cornellpress.cornell.edu.

First published 2021 by Cornell University Press

\section{Library of Congress Cataloging-in-Publication Data}

Names: Stewart, Garrett, author.

Title: The ways of the word : episodes in verbal attention / Garrett Stewart.

Description: Ithaca [New York] : Cornell University Press, 2021. I

Includes bibliographical references and index.

Identifiers: LCCN 2021020723 (print) | LCCN 2021020724 (ebook) |

ISBN 9781501761393 (hardcover) | ISBN 9781501761409 (paperback) |

ISBN 9781501761423 (pdf) I ISBN 9781501761416 (epub)

Subjects: LCSH: English language-Style. | Word (Linguistics) |

English literature-19th century-History and criticism. I

English literature-20th century-History and criticism. I

American literature-19th century-History and criticism. I

American literature-20th century-History and criticism.

Classification: LCC PE1421 .S676 2021 (print) I LCC PE1421 (ebook) I

DDC 808/.042-dc23

LC record available at https://lccn.loc.gov/2021020723

LC ebook record available at https://lccn.loc.gov/2021020724

Cover image: Matej Krén. Cone, oil painting, 2008. Used by permission of the artist. 